\title{
https://doi.org/10.46813/2020-130-015 \\ TORSATRON U-2M WITH REVERSED ADDITIONAL TOROIDAL MAGNETIC FIELD
}

\author{
V.G. Kotenko, R.O. Pavlichenko
}

\section{Institute of Plasma Physics NSC “Kharkov Institute of Physics and Technology”, Kharkiv, Ukraine}

The torsatron U-2M magnetic system is equipped with 16 additional toroidal magnetic field coils. Under normal operating conditions the toroidal field coils create an additional toroidal magnetic field $B_{0}$ the direction of which coincides with the direction of a toroidal magnetic field component $b_{0}$ generated by the torsatron helical coils on the circular axis of the torus. In the torsatron with reversed toroidal magnetic field (RTF) the toroidal field coils create an additional toroidal magnetic field $B_{0 \mathrm{r}}$ of opposite direction. In this study the conditions for developing the magnetic surface configuration with spatial magnetic axis in the torsatron U-2M with RTF are found out and the magnetic surface configuration properties are investigated.

PACS: 52.55.HC

\section{INTRODUCTION}

As is well known in the torsatron U-2M the magnetic system comprises toroidal magnetic field coils [1]. Under normal operating conditions (standard torsatron) the toroidal field coils create the additional toroidal magnetic field $B_{0}$ the direction of which coincides with the direction of the toroidal magnetic field component $b_{0}$ generated by helical coils on the circular axis of the torus.

In the torsatron $\mathrm{U}-2 \mathrm{M}$ with reversed toroidal magnetic field (RTF) the toroidal field coils create an additional toroidal magnetic field $B_{0 \mathrm{r}}$ of opposite direction. A possibility of existence of the closed magnetic surface configuration in a torsatron with RTF has been in part shown by numerical calculations in paper $[2,3]$ where the authors confined themselves to consideration of the magnetic surface configurations with a planar magnetic axis.

In this study the conditions for developing the magnetic surface configuration with spatial magnetic axis in the torsatron U-2M with RTF are found out using the advanced calculation model and the magnetic surface configuration properties are investigated.

\section{CALCULATION MODEL}

The calculation model of the torsatron U-2M magnetic system is schematically represented in Fig. 1,a,b. The following technical characteristics of the real helical coils (HC) were taken into consideration in the calculations:

- the toroidicity $a / R_{0}=0.2618, R_{0}$ is the major radius of the torus, $a$ is the minor radius of the torus (average radius of helical coils);

$-l=2$ is the polarity;

$-m=2$ is the number of helical coil pitches along the torus length;

- there are $N=20$ conductor turns in each helical coil. The total number of helical coil turns with current $I_{\mathrm{h}}$ is $W_{\mathrm{h}}=\operatorname{lm} N=80$;

- each helical coil consists of two equal parts, each part comprises 10 conductor turns;

ISSN 1562-6016. BAHT. 2020. №6(130)

PROBLEMS OF ATOMIC SCIENCE AND TECHNOLOGY. 2020, № 6. Series: Plasma Physics (26), p. 15-18.
- the parts are separated by a diagnostic gap having the width $\Delta S / R_{0}=0.17$ along the torus parallels;

- the central line of the diagnostic gap is the helical base line marked on the torus according to the equalinclined winding law $\theta(\varphi)=2 \arctan (1.3074 \tan \varphi)$, where $\varphi$ is the toroidal angle and $\theta$ is the poloidal angle. The base line is the helical line, along which a supporting structure of the helical coil is assembled;

- the conductor turns are turn-by-turn packed along the helical base line symmetrically on its both side against the diagnostic gap [3].

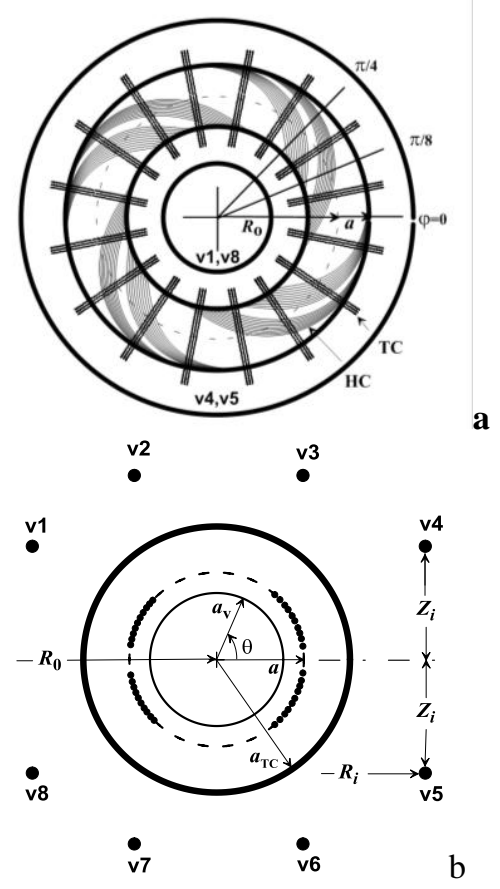

Fig. 1. Calculation model of the U-2M magnetic system: $a$-top view, $b$-poloidal cross-section $\varphi=0$. Compensating coil positions $(v 1, \ldots, v 8)$ are indicated

The following technical characteristics of the additional toroidal magnetic field coils (TC) are taken into consideration in the calculations:

- the number of toroidal field coils is 16 , they are uniformly arranged along the torus length; 
- the average radius of the toroidal field coil is $a_{\mathrm{TC}} / R_{0}=0.4$ (the radial thickness of coil winding $0.113 R_{\mathrm{o}}$ is not taken into consideration);

- each coil comprises 24 conductor turns. The total number of toroidal field coils turns with current $I_{\mathrm{t}}$ is $W_{\mathrm{t}}=384$;

- the coil has a cylindrical form, the cylinder height is $h / R_{0}=0.086$.

Fig. 1 show the layout of the U-2M ring-shaped compensating coils which form a vertical magnetic field compensating the vertical component of the helical coil magnetic field [4]. It is seen from the figure that the device includes 4 pairs of the ring-shaped compensating coils. In each pair the coils of major radius $R_{i}$ are arranged symmetrically at a distance $Z_{i}$ from the equatorial torus plane $(\mathrm{Z}=0)$. Each compensating coil comprises 5 conductor turns. The total number of compensating coil turns with current $I_{\mathrm{v}}$ is $W_{\mathrm{v}}=40$.

Also the device comprises 4 auxiliary ring-shaped correcting coils. They are designed for fine control of the compensating magnetic field value and its radial distribution. The correcting coil radii are very close to the radii $R_{\mathrm{i}}$ of compensating coils $\mathrm{v} 1, \mathrm{v} 4, \mathrm{v} 5, \mathrm{v} 8$ and are arranged like the pairs of compensating coils v1-v8 and v4-v5, respectively. Each correcting coil comprises 8 conductor turns. The total number of compensating coil turns with current $I_{\mathrm{c}}$ is $W_{\mathrm{c}}=32$.

\section{RESULTS OF CALCULATIONS}

Fig. 2 shows the poloidal cross-sections of the magnetic surface configuration with a spatial magnetic axis in the torsatron U-2M with RTF. The cross-sections are spaced around a toroidal angle $\varphi=0, \pi / 8, \pi / 4$ (see Fig. 1). In the figures, the dashed circle represents the torus cross-section $a / R_{0}=0.2618$ with traces of the conductor turns of the helical coils (small black dots). The inner circle shows the cross-section of the U-2M vacuum chamber (the minor radius $a_{\mathrm{v}} / R_{\mathrm{O}}=0.2$ ).

In the general case the spatial magnetic axis has a form of a helical line, which closes up after one goround over the length of the torus $\left(2 \pi R_{0}\right)$ and lies on the surface of an imaginary torus. In Fig. $2, \varphi=\pi / 8$ the crosssection of this torus, i.e. the toroidal projection of the magnetic axis trajectory is represented. The calculations reveal that the magnetic-axis major radius $R_{0 \mathrm{ax}} / R_{0}=0.995$, the magnetic axis minor radius $r_{\mathrm{ax}} / R_{0}=0.025$. It is seen from the figure that the last closed magnetic surface (average radius $r_{\mathrm{lc}} / R_{0}=0.13$ ) fits into the $\mathrm{U}-2 \mathrm{M}$ vacuum chamber. At the configuration edge an isolated chain of magnetic islands is observed. The island magnetic axis closes up after $n_{\varphi}=9$ go-rounds over the toroidal angle $\varphi$ and $n_{\theta}=4$ go-rounds over the poloidal angle $\theta$. The configuration becomes a reality through the helical coil vertical magnetic field compensation with vertical magnetic field of opposite direction. It is formed by the compensating and correcting coils under fulfillment of conditions $I_{\mathrm{v}} \mathrm{W}_{\mathrm{v}} / I_{\mathrm{h}} \mathrm{W}_{\mathrm{h}}=0.5$ and $I_{\mathrm{c}} \mathrm{W}_{\mathrm{c}} / I_{\mathrm{h}} \mathrm{W}_{\mathrm{h}}=0.0889$. To reproduce the magnetic surface configuration with planar magnetic axis $\left(R_{0 \mathrm{ax}} / R_{0}=0.916, r_{\mathrm{ax}} / R_{0}=0\right.$ [3] $)$ the fulfillment of conditions $I_{\mathrm{v}} \mathrm{W}_{\mathrm{v}} / I_{\mathrm{h}} \mathrm{W}_{\mathrm{h}}=0.5$ and $I_{\mathrm{c}} \mathrm{W}_{\mathrm{c}} / I_{\mathrm{h}} \mathrm{W}_{\mathrm{h}}=0.006$ is needed. The planar magnetic axis centering $\left(R_{0 \mathrm{ax}} / R_{0} \rightarrow 1\right)$ demands an essential revision of the U-2M helical coil geometry [5]. The reversed additional toroidal magnetic field value is $B_{0 \mathrm{r}} / b_{0}=-3.624$, i.e. the parameter $K_{\varphi r}=1 /\left(1+B_{0 \mathrm{r}} / b_{0}\right)=-0.381$. In the standard torsatron $\mathrm{U}-2 \mathrm{M}$ with parameter $K_{\varphi}=0.381$ the magnitude of the additional toroidal magnetic field is lesser: $B_{0} / b_{0}=1.624$.

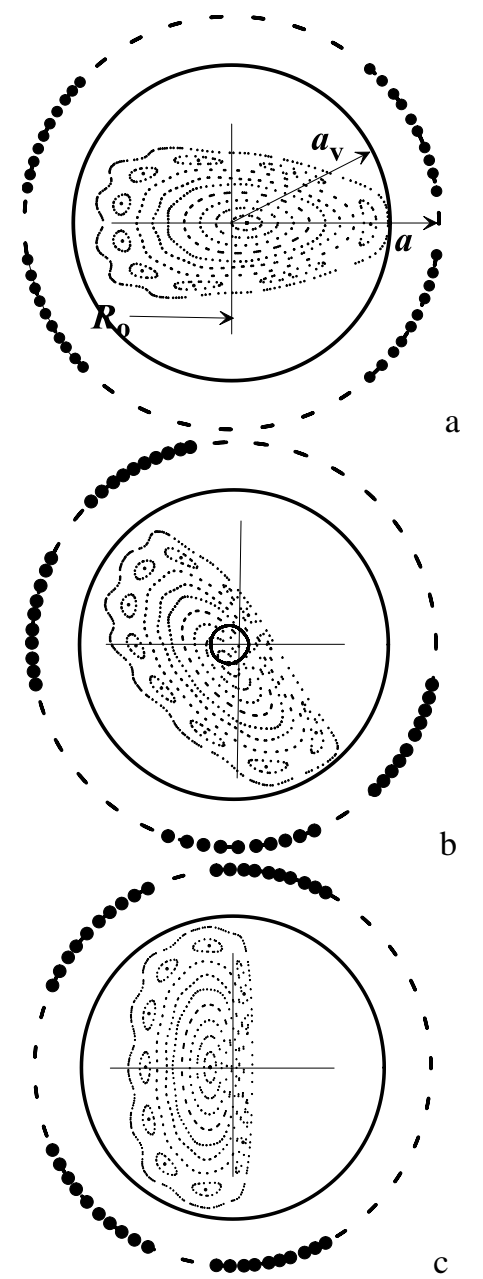

Fig. 2. Poloidal cross-sections of magnetic surfaces in the torsatron $U-2 M$ with RTF calculation model for different $\varphi=0(a), \pi / 8(b), \pi / 4(c)$

Fig. 3, curves 1 presents the magnetic surface parameters as functions of their average radii. There are a magnetic well, $U=0 \rightarrow-0.072$, on the magnetic surfaces of the torsatron $\mathrm{U}-2 \mathrm{M}$ with RTF and the maximum mirror ratio $\gamma=1.12 \rightarrow 1.96$. The rotational transform angle decreases with increase in the magnetic surface average radius, $\mathrm{l}=0.55 \rightarrow 0.43$ (negative shear). The magnetic islands arise on the site of the rational magnetic surface with the average rotational transform angle of the field line $1=n_{\theta} / n_{\varphi}=4 / 9$. To make the information complete, let us consider the magnetic surface configuration in the torsatron U-2M with RTF and in the standard torsatron both with zero current in the correcting coils, i.e. under the fulfillment of conditions $I_{\mathrm{v}} \mathrm{W}_{\mathrm{v}} / I_{\mathrm{h}} \mathrm{W}_{\mathrm{h}}=0.5$ and $I_{\mathrm{c}} \mathrm{W}_{\mathrm{c}} / I_{\mathrm{h}} \mathrm{W}_{\mathrm{h}}=0$. The condition $I_{\mathrm{v}} \mathrm{W}_{\mathrm{v}} / I_{\mathrm{h}} \mathrm{W}_{\mathrm{h}}=0.5$ is fulfilled automatically as the compensating and helical coils and their power supply 
according to the operating electrical circuit of the U-2M device are connected in series, i.e. $I_{\mathrm{v}}=I_{\mathrm{h}}$. The correcting and additional toroidal magnetic field coils are powered via the individual power supplies.

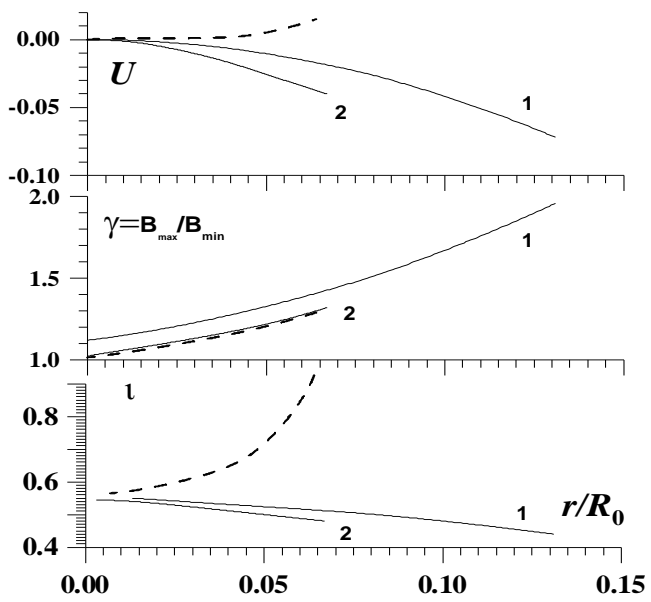

Fig. 3. Rotational transform angle $\imath$ (in $2 \pi$ units), magnetic welNhill $U$, maximum mirror ratio $\gamma$ on the magnetic surfaces as functions of the average magnetic surface radius

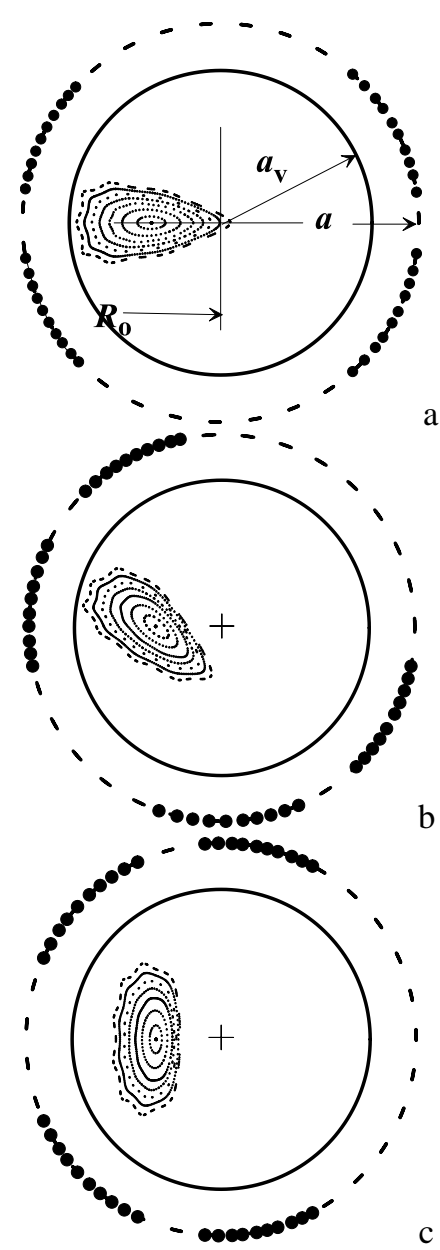

Fig. 4. Poloidal cross-sections of magnetic surfaces in the torsatron $U-2 M$ with $R T F$ calculation model under $I_{c}=0$ for different $\varphi=0(a), \pi / 8(b), \pi / 4(c)$

Fig. 4 shows the poloidal cross-sections of the magnetic surfaces configuration in the torsatron U-2M with RTF under the fulfillment of conditions
$I_{\mathrm{v}} \mathrm{W}_{\mathrm{v}} / I_{\mathrm{h}} \mathrm{W}_{\mathrm{h}}=0.5$ and $I_{\mathrm{c}} \mathrm{W}_{\mathrm{c}} / I_{\mathrm{h}} \mathrm{W}_{\mathrm{h}}=0$. The configuration is small in size and is found displaced inward the torus. The magnetic axis with major radius $R_{0 \mathrm{ax}} / R_{0}=0.911$ and minor radius $r_{\mathrm{ax}} / R_{0}=0.002$ is on the left of the planar magnetic axis position $\left(R_{0 \mathrm{ax}} / R_{0}=0.916, r_{\mathrm{ax}} / R_{0}=0\right.$ [3]).

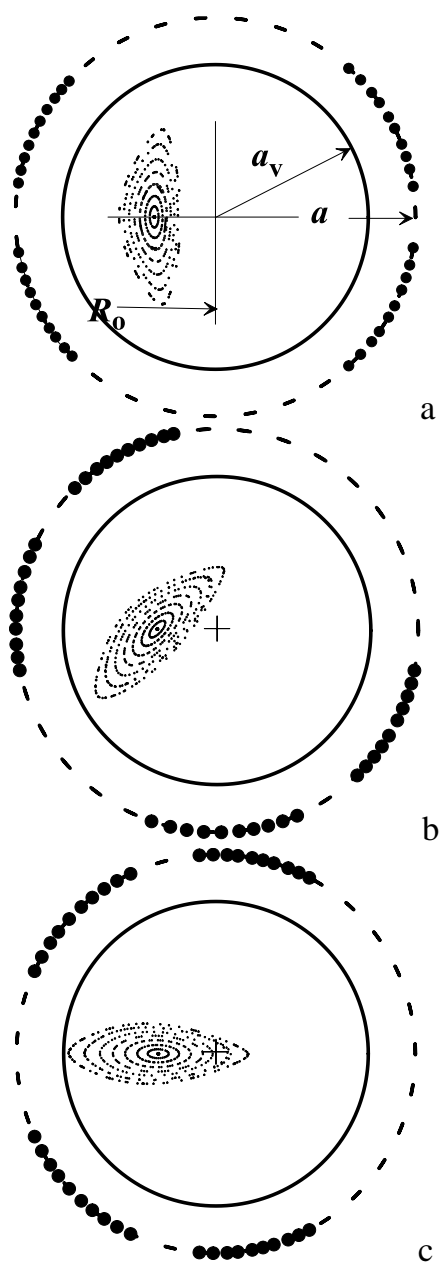

Fig. 5. Poloidal cross-sections of magnetic surfaces in the standard torsatron $U-2 M$ calculation model under $I_{c}=0$ for different $\varphi=0(a), \pi / 8(b), \pi / 4(c)$

When the RTF value $B_{0 \mathrm{r}} / b_{0}=-3$ and the parameter $K_{\varphi \mathrm{r}}=1 /\left(1-B_{0 \mathrm{r}} / b_{0}\right)=-0.5$, the last closed magnetic surface has the average radius $r_{\mathrm{lc}} / R_{0}=0.067$ and its contour has not the points of intersection with the vacuum chamber contour in all the poloidal cross-sections.

The parameters of magnetic surfaces as functions of their average radii are presented in Fig. 3, curves 2. On the configuration magnetic surfaces the magnetic well $U=0 \rightarrow-0.04$ and the maximum mirror ratio $\gamma=1.02 \rightarrow 1.32$ take place. The rotational transform angle decreases with increase in the magnetic surface average radius, $1=0.55 \rightarrow 0.48$ (negative shear).

Fig. 5 shows the poloidal cross-sections of the magnetic surface configuration in the standard torsatron $\mathrm{U}-2 \mathrm{M}$ under the fulfillment of conditions $I_{\mathrm{v}} \mathrm{W}_{\mathrm{v}} / I_{\mathrm{h}} \mathrm{W}_{\mathrm{h}}=0.5$ and $I_{\mathrm{c}} \mathrm{W}_{\mathrm{c}} / I_{\mathrm{h}} \mathrm{W}_{\mathrm{h}}=0$. Similarly, to the torsatron $\mathrm{U}-2 \mathrm{M}$ with RTF the magnetic surface configuration is small in size and displaced inward the torus but to a lesser degree.

The magnetic axis with major radius $R_{0 \mathrm{ax}} / R_{0}=0.922$ and minor radius $r_{\mathrm{ax}} / R_{0}=0.002$ is on the right of the planar magnetic axis position). When the value $B_{0} / b_{0}=1$ 
the parameter $K_{\varphi}=0.5$, the last closed magnetic surface has the average radius $r_{\mathrm{lc}} / R_{0}=0.064$ and its contour has not the points of intersection with the vacuum chamber contour in all poloidal cross-sections. So, in the standard torsatron model with parameter $K_{\varphi}=0.5$ the additional toroidal magnetic field magnitude is three-fold lesser than in the torsatron with RTF model with parameter $K_{\varphi \mathrm{r}}=-0.5$.

The magnetic surfaces parameters as functions of their average radii are presented in Fig. 3 by dashed curves. It is seen from the figure, that on the magnetic surfaces the magnetic hill $U=0 \rightarrow 0.015$ and the maximum mirror ratio $\gamma=1.015 \rightarrow 1.3$ take place. The rotational transform angle increases with increase in the magnetic surface average radius, $\mathrm{t}=0.56 \rightarrow 0.92$ (positive shear).

\section{CONCLUSIONS}

The calculations evidence that in the torsatron $\mathrm{U}-2 \mathrm{M}$ with RTF $\left(B_{0 \mathrm{r}} / b_{0}=-3.624\right)$ the magnetic surface configuration with a spatial magnetic axis is possible due to the relevant current value in the correcting coils $\left(I_{\mathrm{c}} \mathrm{W}_{\mathrm{c}} / I_{\mathrm{h}} \mathrm{W}_{\mathrm{h}}=0.0889\right)$. The configuration dimensions, magnetic axis parameters, maximum values of the mirror ratio $\gamma$ and the magnetic well values on the magnetic surfaces are comparable with magnetic surface parameters which can be realized in different magnetic configurations of the standard torsatron U-2M [4]. Unlike the standard torsatron in the torsatrons with RTF the rotational transform angle value is maximal on the magnetic axis and drops by $\sim 20 \%$ in the magnetic surface configuration edge (negative shear, tokamak-like dependence). The properties of magnetic surface configurations with zero current in the correcting coils are similar to the properties of the magnetic surface configurations with planar magnetic axis in the standard torsatron and in the torsatron with RTF, respectively.
In addition, in the torsatrons with RTF the magnetic surface patches with a minimum surface curvature are out of the torus surface area under the helical coils (see Figs. 4, 5). This feature makes possible the RF-antenna placement facing the patches in order to decrease the diverted plasma flow detrimental effects on the processes of RF-plasma generation and heating which are inherent in the standard torsatron. At the same time, the alternating on the two operating regimes of the facility with and without RTF can promote a more efficient process of vacuum chamber wall conditioning. To evaluate the RTF effect on the torsatron U-2M plasma behaviour a series of experiments can be performed in the torsatron U-2M with RTF using reduced $\sim 0.3 b_{0}$ values only. The restriction occurs because the load-bearing unit of the $\mathrm{U}-2 \mathrm{M}$ magnetic system [1] is not designed for change in the direction of ponderomotive interaction force between a helical coil currents and an additional toroidal magnetic field.

\section{REFERENCES}

1. V.E. Bykov et al. // Fusion Technology. 1990, v. 17, p. 140 .

2. V.G. Kotenko, S.S. Romanov, N.T. Besedin // Ukr. Fiz. Zh. 2001, № 46, v. 11, p. 1127-1132.

3. V.G. Kotenko, D.V. Kurilo, Yu.F. Sergeyev, Ye.D. Volkov. Plasma Devices and Operations. 2007, v. 15, № 4, p. 253-262.

4. A.A. Shishkin. Preprint, KhIPT 2005-2, Kharkov, 2005.

5. V.G. Kotenko // Problems of Atomic Science and Technology. Series «Plasma Physics» (14). 2008, № 6, p. 37-39.

Article received 12.10.2020

\section{ТОРСАТРОН У-2М С ОБРАЩЕННЫМ ДОПОЛНИТЕЛЬНЫМ ТОРОИДАЛЬНЫМ МАГНИТНЫМ ПОЛЕМ}

\section{В.Г. Котенко, Р.О. Павличенко}

Магнитная система торсатрона У-2М содержит 16 катушек дополнительного тороидального магнитного поля. В стандартном режиме катушки создают дополнительное тороидальное магнитное поле, направление которого совпадает с направлением тороидальной компоненты магнитного поля, создаваемой винтовыми обмотками торсатрона на круговой оси тора. В торсатроне с обращенным дополнительным тороидальным магнитным полем (ОТП) эти катушки создают дополнительное тороидальное магнитное поле противоположного направления. С помощью уточненной расчетной модели выясняются условия реализации в торсатроне У-2М с ОТП конфигурации магнитных поверхностей с пространственной магнитной осью и исследуются ее параметры.

\section{ТОРСАТРОН У-2М 3 ОБЕРНЕНИМ ДОДАТКОВИМ ТОРОЇДАЛЬНИМ МАГНІТНИМ ПОЛЕМ}

\section{В.Г. Котенко, Р.О. Павліченко}

Магнітна система торсатрона У-2М має в своєму складі 16 котушок додаткового тороїдального магнітного поля. У стандартному режимі котушки створюють додаткове тороїдальне магнітне поле, напрямок якого співпадає 3 напрямком тороїдальної компоненти магнітного поля, яке створюється гвинтовими обмотками на круговій осі тору. У торсатроні з оберненим додатковим тороїдальним полем (ОТП) ці котушки створюють магнітне поле протилежного напрямку. 3 допомогою уточненої розрахункової моделі з'ясовуються умови реалізації в торсатроні У-2М з ОТП конфігурації магнітних поверхонь 3 просторовою магнітною віссю та досліджуються її параметри. 